\title{
Hungarian vocational education teachers' views on their pedagogical knowledge and the information sources suitable for their professional development
}

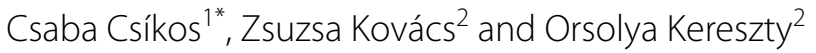

${ }^{*}$ Correspondence:

csikos.csaba@tok-elte.hu

${ }^{1}$ Department

of Mathematics, Faculty

of Primary and Pre-School

Education, ELTE, Budapest,

Hungary

Full list of author information

is available at the end of the

article

\begin{abstract}
Background: Vocational education teachers are key participants in the renewal of the Hungarian vocational educational system. Their professional development (as indicated by their learning activities, learning targets and information sources) contains both the input for improving their teaching and the findings essential for affecting future improvements. The aim of this questionnaire survey was to explore Hungarian vocational education teachers' views and judgements on three interrelated phenomena: their learning activities, their opinion regarding the importance of pedagogical knowledge and the efficiency and usage of information sources relevant to their professional development.
\end{abstract}

Methods: A total of 1131 teachers from 37, randomly selected vocational education schools completed a questionnaire based on five subscales, each containing five-point Likert-scales: (1) teachers' learning activities, (2) judgment of their preparedness in pedagogical knowledge, (3) judgment on the importance of their pedagogical knowledge components, and (4) the efficiency and (5) usage of information sources in furthering their professional development.

Results: All subscales display appropriate reliability (Cronbach's alpha ranged from .65 to .94). The study provides the descriptive statistical values for each questionnaire item, the relationships between subscales and the connections between the subscales and background variables, such as gender, career level and school type.

Conclusion: This explorative study possesses theoretical relevance in developing a questionnaire that consists of five reliable subscales, all of which can later be used for either detecting changes in teachers'views or measuring the effectiveness of intervention programs and professional development training sessions designed for vocational education teachers. The study's practical relevance lies in its explorative nature: decision makers are provided with ample evidence indicating the potential advantages and obstacles vocational education teachers face in their attempt to work more efficiently.

Keywords: Vocational education teachers, Teachers' views, Professional development 


\section{Background}

\section{The importance of researching vocational education teachers' views}

Vocational education teachers are key participants in the overhaul of the Hungarian vocational education system that is currently underway. Vocational education teachers' views, their values and judgements are of utmost importance in advancing their professional development while also assessing how system-level regulations can best assist them. In the previous decades, the overall importance of investigating teachers' views regarding different issues in education has been well-documented. The basic assumption is that teachers' views influence their classroom practices and consequently have an indirect effect on students' performance or attitudes as a reflection of the teaching practice.

How educators' views are related to their in-class teaching practices is an issue that has already been explored by a variety of research methods. The main difficulty involved in such investigations is not in mapping teachers' views [a process possessing its own, well-established theory and practice since at least the seminal article by Pajares (1992)], but in exploring both teachers' classroom practice and how this relates to their beliefs and experiences. The challenge of scientifically describing teachers' classroom practices as a function of their views has been accepted by many scholars: Brickhouse (1990) interviewed three science teachers in order to map their opinions, followed by observing many lessons to determine a definite correlation between the two constructs. While several studies found the relationship between teacher views and classroom practice to be a controversial one (Savasci-Acikalin 2009), it must be mentioned that these analyses primarily dealt with pre-service teachers (e.g., Mellado 1998; Hancock and Gallard 2004). In a recent empirical model proposed by Palak and Walls (2009), a combination of large-sample qualitative and quantitative methods revealed how teachers' views surrounding the usage of technology changed their instructional practice. Nonetheless, any relationship between teachers' views and practice may be twofold: the reverse may also be true regarding the connection between teachers' views and their professional practice because teachers' ongoing classroom practices may also shape their beliefs in connection to teaching and learning. In a model proposed by Guskey (2002), teachers' beliefs are connected to the outcome of alterations in teaching practices and the resulting changes experienced in students' performance. On the contrary, the prerequisite role of teachers' views in teachers' actions (or the lack thereof) is equally feasible in the case of teachers who are at the beginning of their career (Pajares 1992).

In reference to terminology, we would like to state that-in accordance with what Hofer and Pintrich implicitly suggest in their volume on personal epistemologies (Hofer and Pintrich 2002) - several synonyms and special terms are used when discussing the subjective truths people hold and communicate. Such synonyms may include the following: assumptions, views, opinions, ways of knowing, etc. In the literature in Hungarian a term equivalent to views is generally preferred, so allowing for some alterations and synonyms, this is the term primarily used in this study.

\section{Research in Hungary on vocational education teachers' views and experiences}

Among teachers, educators at vocational schools possess a special role within the Hungarian education system due to the fact that the types of schools being offered in 
Hungarian secondary education are changing. This present investigation occurred right before new types of upper secondary schools were introduced into the education system. For more than two decades before this change, vocational education took place in two types of schools. Secondary vocational schools (szakközépiskola) have long enjoyed the preference of lay people, who considered this kind of institution to be the best choice $^{1}$ since 5 th-year students could receive a certificate for completing vocational education in addition to achieving the maturation exam taken at the end of the 4th year in upper secondary level schooling. In contrast to this form of school, the second possibility, vocational schools (szakiskola), offered students vocational training and exposure to some academic subjects for 4 years. In many cases, the same institution could provide both vocational and secondary vocational training in separate classes, therefore the vocational education teachers who participated in this survey may have worked either in one of the two types of vocational training or simultaneously in both types.

Previous research conducted in Hungary on teachers' views about learning and teaching involved teachers from gymnasium and secondary vocational schools, while teachers employed at vocational schools were not included. A large sample study conducted in the 90s revealed several tendencies in which gymnasium teachers were shown to differ from vocational secondary teachers. One striking contrast concerned the usage of instructional strategies: vocational education teachers employed the methods of working in dyads and classroom discussion while games were initiated less frequently in comparison to their gymnasium teacher counterparts, who were more likely to employ project work as well as ICT- and multimedia-based learning methods. Another difference emerged regarding the preference for summative evaluation over formative assessment. Several aspects of teachers' views, however, revealed no difference between gymnasium and vocational education teachers; these views referred to the recognized importance of motivation and acknowledging the role of factors related to family background (Golnhofer and Nahalka 2001).

\section{Vocational education teachers' views and professional development as analyzed in previous international studies}

International surveys and experiments have underscored several important characteristics pertinent to how vocational education teachers think, thereby forming a source of findings upon which any decisions concerning their professional development should be based. In general, vocational education teachers are inclined to support meaningful changes in vocational education, including their professional development (Greenan et al. 1998). Teachers' professional development highly depends on the values they have, including their beliefs regarding the importance of what knowledge teachers must possess for working in vocational education. In addition, the possible sources of information available for their use and the actual learning opportunities and activities they judge as important will enact an influence on their professional development.

\footnotetext{
${ }^{1}$ According to the results of a nationwide Gallup poll, almost half of the population chose secondary vocational school when replying to the question: "Which type of school is most worth being selected by students after finishing elementary school?" (see Imre and Lannert 2000).
} 
A widely used term for quite some time, Shulman's (1987) concept of pedagogical content knowledge (PCK) places PCK at the very center of teachers' professional development. According to this concept, no matter the subject taught by a teacher, a common system of knowledge deemed necessary for teaching does exist in reference to issues such as how to conduct lessons, awareness of instructional techniques and strategies, knowledge about students and their characteristics and many other aspects concerning the creation of a powerful learning environment. The Shulmanian sense of PCK can be found in the current research examining vocational education teachers' knowledge, such as in the study conducted by Fritsch et al. (2015), who investigated business-economics vocational education teachers' knowledge and how PCK is connected to this field of instruction.

The possibly wide range of opportunities available for teachers' professional development has also been discussed in the literature (see Guskey 2002; Birman et al. 2000). These opportunities contain sites and occasions including formal in-service teacher trainings, informal and non-formal discussions, observations and the significant role played by the overall institutional climate. Teachers' professional development can be influenced by many variables, among which those of gender, experience and the type of vocational education all seem to occupy a central position in the empirical research. Vocational education teachers' gender, for example, was examined as a relevant background variable in several previous investigations (see Gordon 1998; Greenan et al. 1998; Hof and Leiser 2014; Wicklein and Rojewski 1995). Although there is a gender bias in reference to the type of institution, relevant gender differences concerning teachers' values and learning activities have yet to be found. In Estonia, researchers (Sirk et al. 2016) have provided data on several aspects of vocational teachers' work, out of which we highlight the results regarding how highly experienced vocational education teachers view the pedagogical knowledge required for their work and how they cope with changes in the profession. In both areas, the results underscored an emphasis on the need to have skills in using computers and other technical tools.

The new possibilities and demands stemming from ICT-based innovation, i.e. usage of video tutorials, networking through social media and the overall awareness of values shared by new student generations (often labelled as X, Y or Z generations), have not been targeted in empirical surveys among vocational education teachers. However, it has been revealed that the best practice offered in how to utilize various ICT tools such as wiki, social media or serious games may come from vocational and professional courses held at universities (Littlejohn et al. 2012). Cardoso and Coutinho (2011) additionally reported promising results in secondary school vocational education in connection to the motivating and inspiring usage of digital tools.

\section{Aims and hypotheses}

The strategic aim of this research was to provide data and evidence upon which the renewal of the Hungarian vocational education system could be based. Vocational education teachers, the most important human resources in this field, expressed their opinions about and assessed several phenomena in reference to their professional learning. We hypothesized that by means of administering a reliable questionnaire, our vocational education system would receive a rich source of information upon which the design and 
implementation of various opportunities for teachers' professional development could then be based.

In accordance with the literature review, we aimed to measure vocational education teachers' assessment of their learning opportunities, the extent to which they possess a sense of preparedness in different areas of knowledge, how important they consider these knowledge components to be and how they judge the efficiency and usage of different information sources for their professional development.

Since the population of vocational education teachers is far from homogeneous, we hypothesized that teachers' gender, their professional career level and the type school they work in may influence their replies. At the same time, where no such effect is found, this investigation may reveal the existence of core views held by teachers independently of their background characteristics.

\section{Methods}

\section{Sample}

The population examined in the current study entirely consisted of upper secondary teachers in Hungary who work in either a vocational school (szakiskola) or secondary vocational school (szakközépiskola). Both academic and vocational subjects are taught in these two types of upper secondary-level schools (Cedefop 2011).

In the sampling procedure, we decided to use systematic sampling, one type of random sampling method. First, the frequency interval was set at ten; in other words, every tenth school was selected. Out of the whole list containing 370 schools, the tenth, twentieth, thirtieth, etc. were chosen. Since the complete list of schools had been arranged according to the alphabetical list of geographical locations, this systematic sampling provided a simple and unbiased selection of 37 schools in total. After receiving information about the research project, the school principals were asked to send the questionnaire to all the teachers in the given school. A total of 1131 questionnaires were returned, an acceptable number for computing reasonably precise estimates in connection to population characteristics. Based on a system-level average, roughly thirty teachers per state-owned institution participated in the survey, thereby bringing the response rate fairly close to $100 \%$. Out of the 1131 participants, 1073 provided data on gender: 444 respondents were male while 629 were female.

Respondents indicated their teaching career level ${ }^{2}$ in $91.7 \%$ of the cases. The surveys were filled out by twenty-one teachers at the Probationer level, while the rest included 812 Teacher I, 161 Teacher II, 43 Master Teacher and two Research Teacher cases. In subsequent analyses the two Research Teacher cases were omitted due to representing too small of a subsample.

As for the types of schools where the teachers involved in this research ${ }^{3}$ were employed, 436 teachers were only working in secondary vocational schools, 123 were only teaching in vocational schools and 492 taught classes belonging to both types of vocational schooling.

\footnotetext{
${ }^{2}$ In Hungary, there are five levels in teachers' life-time career model. The three mandatory stages are: Probationer, Teacher I and Teacher II. The upper two stages of Master Teacher and Research Teacher are optional.

3 In line with what we have described in "Research in Hungary on vocational education teachers' views and experiences" section there are three types of institutions: vocational schools, vocational secondary schools, and mixed type of schools with both types of classes.
} 


\section{Questionnaire}

Bearing the title of Vocational Education Teachers' Pedagogical Knowledge, the questionnaire contains eleven numbered questions (item bunches); the current study focuses on the quantifiable items that follow below.

\section{Teachers' learning activities}

The first part of the questionnaire consisted of eight items related to the area of teachers' learning activities. Five items were borrowed from the questionnaire developed by Oude Groote Beverborg et al. (2015). Three further items were developed by the authors to reflect traditions in the Hungarian educational system. As a group of experts, the authors agreed upon which items from the original questionnaire could be translated unambiguously into Hungarian while also representing the subscales appropriately.

\section{Items on teachers' knowledge}

These items were selected from Hungarian legal documents (such as the 8/2013 Decree of the Ministry of Economics) describing what knowledge components vocational education teachers must possess at the end of their training. Fifteen such items were selected. A twin table format was used for measuring how participants evaluated their level of preparation regarding each knowledge component as well as how they assessed their importance. In addition to the items found in legal documents, four other items that focused on ICT-related competences were developed by us. In all cases a five-level Likert-scale was utilized.

\section{Sources of professional development}

These items were developed by the authors of this paper, either by selecting six items from the literature review (Guskey 2002; Birman et al. 2000) or by referring to certain challenges teachers currently face. In a twin table format, participants were additionally asked to assess areas of their professional development according to the extent of efficiency and usage they experienced regarding these aspects. Both features were weighed according to the five-point Likert-type scale. The possible, listed sources included trainings for in-service teachers, conferences, journals, discussions with colleagues, participation in research projects and the Internet.

\section{Further variables}

In order to make comparisons between different groups possible, several background variables of a demographic nature were asked at the end of the questionnaire. These factors referred to teachers' gender, age, teaching career-level and whether the teacher worked in vocational, secondary vocational classes, or both.

\section{Procedure}

In this study the paper-and-pencil version of the questionnaire was used. The questionnaires were collected from the schools and coded by an expert based on the Excel data file template created by the first author of this study. The data were then transferred to SPSS and analyzed by means of descriptive statistics, statistical comparisons, correlation analyses and multivariate analyses. 
We conducted both item-level and subscale-level analyses. In doing so, the three subscales will be referred as Teachers' learning activities, Teacher knowledge (in training and the importance of) and Sources of professional development (efficiency and usage).

\section{Results}

In this empirical and quantitative research report, the descriptive statistical results for three parts of the questionnaire will be presented first. Due to the large sample size, the mean and standard deviation values provide a precise estimation of the corresponding population means and SDs. Following this examination, statistical comparisons (pairedsamples t-tests) enabled by the twin table format will be presented. The internal consistency and internal structure have been investigated (Cronbach's alpha and cluster analysis) for all three parts of the questionnaire. Finally, we computed the correlations among the three parts while further correlations regarding demographic background variables were calculated separately.

\section{Teachers' learning activities}

The reliability of this part of the questionnaire was .73 (Cronbach's alpha), therefore the summed Likert-scale provided a reliable variable. The mean and SD values of the eight items belonging to this subscale are presented in Table 1.

The strongest agreement was reached concerning the first item, while the second item was judged the least positively. In general, teachers relayed positive assessments in connection to the items regarding their learning activities as professionals. As for the distribution of the data, the relatively large SD for the last item (institutional support) is due to the fact that $9 \%$ of the teachers viewed this item negatively. The same $9 \%$ value emerged in connection with the second item, also accompanied by the lowest mean value.

\section{Teacher knowledge}

This section of the questionnaire contained nineteen items repeated twice. Both the preparation and the importance subscales proved to be highly reliable. Cronbach's $\alpha$ was .94 for the preparation scale, and .92 for the importance scale. Table 2 presents how teachers judged the appropriateness of their preparation before they started working in vocational education.

In general, teachers moderately agreed that the preparation had been appropriate. The only mean value less than 3.00 regarded the category of a proactive lifestyle, while only

Table 1 Mean and SD values for the items of the teachers' learning activities subscale

\begin{tabular}{|c|c|c|}
\hline Item & Mean & SD \\
\hline For the conduct of our jobs, the members of my team need information from each other & 4.51 & .73 \\
\hline We agree on what quality represents for our team & 3.60 & .92 \\
\hline $\begin{array}{l}\text { I can remain calm when confronted with difficulties in my work because I know that I can fall back } \\
\text { on my competences }\end{array}$ & 4.08 & .77 \\
\hline Teachers can learn from each other by means of attending and observing each other's lessons & 4.17 & .87 \\
\hline I compare my performance with how I performed 1 year ago & 4.27 & .82 \\
\hline It is clear to me how my work fits the aims of my institution & 4.31 & .83 \\
\hline My colleagues listen to my pedagogical experiences & 4.03 & .87 \\
\hline My institution supports my participation in in-service teacher training programs & 4.15 & 1.08 \\
\hline
\end{tabular}


Table 2 Items on being prepared for the teaching profession as judged by vocational education teachers

\begin{tabular}{|c|c|c|c|}
\hline \multicolumn{2}{|c|}{ Item } & \multirow{2}{*}{$\begin{array}{l}\text { Mean } \\
2.96\end{array}$} & \multirow{2}{*}{$\frac{\text { SD }}{1.20}$} \\
\hline 7 & Familiarity with the pedagogy of a proactive lifestyle & & \\
\hline 16 & Knowledge of the characteristics of the $X, Y$ and $Z$ generations & 3.13 & 1.29 \\
\hline 8 & Knowledge of experience-centered vocational practical training & 3.19 & 1.24 \\
\hline 18 & Knowledge of the importance of video tutorials available on the internet & 3.28 & 1.24 \\
\hline 6 & Knowledge of values and the crisis of values in the modern age & 3.31 & 1.18 \\
\hline 5 & Planning the process of vocational practical training & 3.33 & 1.30 \\
\hline 2 & Pedagogical characteristics of vocational practical training & 3.36 & 1.22 \\
\hline 19 & Differentiation between visual and verbal learners & 3.40 & 1.11 \\
\hline 12 & Knowing how to foster self-controlling responsibility & 3.41 & 1.10 \\
\hline 11 & Familiarity with developing problem solving skills during vocational practical training & 3.47 & 1.09 \\
\hline 17 & Knowing how to search for information on the Internet & 3.47 & 1.26 \\
\hline 13 & Knowing how to shape teamwork creatively & 3.52 & 1.09 \\
\hline 14 & Awareness of the openness of self-development in a profession & 3.65 & 1.04 \\
\hline 1 & Awareness of students' developmental phases & 3.67 & 1.03 \\
\hline 10 & Awareness of the role of self-determination when working & 3.68 & 1.09 \\
\hline 4 & Awareness of the task system necessary to reach goals & 3.73 & .94 \\
\hline 9 & Knowing the role of positive and negative feedback as motivators & 3.76 & 1.01 \\
\hline 3 & Knowledge of pedagogical goals & 4.03 & .92 \\
\hline 15 & Awareness of the importance of personal role modeling & 4.11 & .96 \\
\hline
\end{tabular}

two items yielded mean values above 4.00. The terms pedagogical goals and the role of personal role-modeling appear to be sufficiently present in pre-service teacher training. As for the SD values, some items proved to be divisive: e.g., knowledge of the $\mathrm{X}, \mathrm{Y}$ and $\mathrm{Z}$ generations, or planning the process of vocational practical training.

Table 3 presents the mean and SD values for the same 19 items concerning their assessed importance in vocational education teachers' work.

According to Table 3, all the listed knowledge items were judged positively with respect to their importance. Knowledge regarding a proactive lifestyle was the only item resulting in a mean value below 4.00. Some items drew an extremely high level of agreement among teachers. Awareness concerning the role of personal role modeling garnered the highest mean value.

The corresponding mean values of preparedness and importance for each item were compared with paired-samples t-tests. Not surprisingly, in all cases the perceived importance resulted in a significantly higher mean ( $\mathrm{p}<.001$ in all cases). The largest differences can be observed between the corresponding mean values of the experiencecentered training and the $\mathrm{X}, \mathrm{Y}, \mathrm{Z}$ generation items. In these two items, teachers felt that they had not been adequately prepared in these areas during their pre-service education in comparison to how important they later proved to be.

The twin table arrangement rendered the questionnaire especially suitable for analyzing the correlation between perceived importance and how teachers felt concerning their preparedness for the teaching profession. Due to the large sample size, all correlations proved to be significant $(\mathrm{p}<.001)$, prompting us to turn our attention to the magnitude of the $\mathrm{R}^{2}$ values. In other words, the squared correlation coefficient is the explained variance indicating the strength of the relationship between the two variables. 
Table 3 Importance of different pedagogical knowledge items as ascertained by vocational education teachers

\begin{tabular}{llll}
\hline Item & & Mean & SD \\
\hline 7 & Familiarity with the pedagogy of a proactive lifestyle & 3.90 & .95 \\
19 & Differentiation between visual and verbal learners & 4.21 & .73 \\
18 & Knowing the importance of video tutorials available on the Internet & 4.22 & .85 \\
12 & Knowing how to foster self-controlling responsibility & 4.26 & .82 \\
13 & Knowing how to shape team work creatively & 4.28 & .79 \\
16 & Knowing the characteristics of the X, Y and Z generations & 4.32 & .83 \\
1 & Knowing students' developmental phases & 4.34 & .74 \\
2 & Pedagogical characteristics of vocational practical training & 4.34 & .82 \\
6 & Knowing the values and the crisis of values on the modern age & 4.35 & .76 \\
14 & Knowing the openness of self-development in a profession & 4.35 & .79 \\
5 & Planning the process of vocational practical training & 4.37 & .86 \\
8 & Knowing the experience-centered vocational practical training & 4.38 & .83 \\
10 & Knowing the role of self-determination when working & 4.41 & .72 \\
9 & Knowing the role of positive and negative feedback as motivators & 4.42 & .73 \\
4 & Knowing the task system necessary to reach goals & 4.44 & .73 \\
11 & Knowing how to develop problem solving during vocational practical training & 4.46 & .70 \\
17 & Knowing how to search for information on the Internet & 4.46 & .72 \\
3 & Knowing the pedagogical goals & 4.49 & .71 \\
15 & Knowing the importance of personal role modeling & 4.67 & .59 \\
\hline & & &
\end{tabular}

The explained variance values ranged between 4 and 18\%, indicating a moderate level of strength in perceived causality. These relatively low $R^{2}$ values indicate that it was not mainly the level of preparation that made an issue more or less important in teachers' opinion; we can therefore conclude that the two scales worked well independently of one another.

\section{Sources of professional development}

The questionnaire listed six possible information sources and requested teachers to evaluate both the source's efficiency and their usage of each information source. The results are summarized in Table 4 . The reliability for both scales proved to be marginally acceptable (Cronbach- $\alpha$ was .68 for efficiency and .65 for usage.).

Table 4 suggests that teachers possessed strikingly marked opinions regarding the efficiency of different information sources. With the exception of the Internet, the frequency of usage was usually lower on average than perceived efficiency was. The largest gap between mean values can be observed in the case of participation in research projects. Albeit the efficiency of this was not positively judged, the rather low level of its usage indicates the potential to improve teachers' participation in this source of professional development. From our perspective, it was disappointing to see that both the training programs and the conferences were gauged rather neutrally as information sources. In our study the proposed activities and sources for vocational education teachers' professional development remained well within the boundaries of school and academic life. A possible extension of this part of our survey may involve participation in the work-life community. In a Swedish experiment, Andersson and Köpsén (2015) revealed the importance of such "boundary crossings" in teachers' professional development. 
Table 4 Efficiency and usage of different information sources in teachers' professional developed as judged by the teachers

\begin{tabular}{llllll}
\hline Item & \multicolumn{2}{l}{ Efficiency } & & \multicolumn{2}{l}{ Usage } \\
\cline { 2 - 3 } & Mean & SD & & Mean & SD \\
\hline Trainings for in-service teachers & 3.55 & 1.10 & & 3.14 & 1.35 \\
Conferences & 3.13 & 1.13 & & 2.54 & 1.29 \\
Journals & 3.98 & .88 & & 3.76 & 1.07 \\
Discussions with colleagues & 4.57 & .67 & & 4.50 & .72 \\
Participation in research projects & 3.26 & 1.26 & & 2.20 & 1.34 \\
Internet & 4.34 & .77 & & 4.44 & .82 \\
\hline
\end{tabular}

A paired-samples $\mathrm{t}$-test showed that $(\mathrm{p} \leq .001)$ the difference was statistically significant in all cases. The correlations between the corresponding variables (efficiency and usage in six cases) were all significant as well $(\mathrm{p}<.001)$. The explained variance ranged from 16 to $45 \%$. These determination coefficients are relatively higher than the values in the Teacher knowledge section of the questionnaire, which can be explained by the very subjective and individual nature of the information gained here.

\section{Correlations among subscales of the questionnaire}

In order to provide a holistic picture of the overall connections among subscales, the five summed scales have been computed. Their inter-correlations are presented in Table 5 .

Not surprisingly, all correlation coefficients among the main variables proved to be significant. Since even .05 coefficients are significant in such a large sample, the main question posed in Table 5 is whether the difference among the coefficients is significant. The many possible pairwise comparisons of overlapping and non-overlapping coefficients showed that-as a rule of thumb-differences greater than .07 between two coefficients in the matrix are significant. We can therefore state with assurance that the usage of information sources and the perceived efficiency of those sources are more strongly correlated than any other correlations in the matrix.

\section{Connections with background variables}

\section{Gender differences}

In such large samples, nuances between mean values are statistically significant; at the same time, this does not mean that they can be meaningfully interpreted. Furthermore, it must be stressed that variations in values do not establish educational decisions. In truth, differences as small as .1 on a five-point Likert-scale are numerically significant,

Table 5 Inter-correlations among the subscales of the questionnaire

\begin{tabular}{lllll}
\hline & $\begin{array}{l}\text { Learning } \\
\text { activities }\end{array}$ & $\begin{array}{l}\text { Knowledge- } \\
\text { preparation }\end{array}$ & $\begin{array}{l}\text { Knowledge- } \\
\text { importance }\end{array}$ & $\begin{array}{l}\text { Information- } \\
\text { efficiency }\end{array}$ \\
\hline Knowledge-preparation & .32 & & & \\
Knowledge-importance & .46 & .46 & .38 & \\
Information-efficiency & .27 & .31 & .31 & .56 \\
Information-usage & .26 & .35 & &
\end{tabular}

All correlation coefficients are significant at $p<.001$ level 
yet do not provide a large enough basis for meaningful interpretation or the reaching of new conclusions. Male-female differences demonstrate the following pattern.

Teachers' learning activities were judged rather similarly by the two groups. In total, only three significant contrasts emerged out of the eight items, resulting in a .13-.21 difference in magnitude. There is no general agreement concerning how large differences shown on a five-point Likert scale should be considered as meaningful and relevant. A subjective view from Dawes (2008) suggests half of a scale-point as a threshold value.

In the second subscale, several items exhibited significant gender difference; only two of them, however, approached the .5 magnitude of difference. Both items concerned the perceived level of having been adequately prepared as pre-service vocational education teachers, demonstrated by the categories listed as Pedagogical characteristics of vocational practical training and planning the process of vocational practical training. In both cases women felt that the extent of preparation received in these two items had been more appropriate.

No relevant differences could be observed in the third subscale: the maximum difference between males and females was .24, indicating a higher level of perceived importance of in-service teacher training as a source of information for their work among male educators. Females judged the importance of participation in research projects more favorably, by a difference of .23.

When comparing the mean values of the summed scales, there were no significant gender differences in the third subscale, which dealt with information sources. Differences on the scales were significant for the following items, demonstrating p values .005 (learning activities), .004 (knowledge-preparation), and .003 (knowledge-importance).

\section{Teachers' career level}

We examined what influence the teachers' current career level may play via a series of ANOVA tests. Teachers possessing a higher career standing generally judged their learning activities more positively. The between-group differences were significant, however, the eta-squared values (estimate of effect size) were small at $2.2 \%$. As for the second part of the questionnaire, the perceived level of preparedness in the listed pedagogical knowledge items showed no significant differences among various career level groups. Nevertheless, the judged importance of the knowledge items indicated that career level exercised a small effect $\left(\eta^{2}=1.5 \%\right)$. In spite of the fact that the judged efficiency of information sources exhibited no significant differences, teacher' usage of these sources naturally revealed a relatively high effect related to career standing $\left(\eta^{2}=3.2 \%\right)$. According to the results, the Teacher I career stage is least associated with the use of different information sources for their professional development. The other three groups (Probationers, Teacher II and Master Teacher groups) did not differ significantly from one another.

\section{Type of classrooms where the teacher works}

The type of classrooms where the teachers work defined three other subgroups in the sample. The results suggest that the type of classroom where the teacher works does not enact a strong influence on teachers' assessment of their learning activities $(\mathrm{p}=.40$, $\eta^{2}=.2 \%$ ). The perceived level of preparedness for pedagogical knowledge items is influenced by the type of classroom $\left(\mathrm{p}=.007, \eta^{2}=1 \%\right)$, similarly to the judged importance of 
those knowledge items $\left(\mathrm{p}=.011, \eta^{2}=.9 \%\right)$. In both cases those who teach in vocational schools only had higher mean values. Although the effect sizes were small, it is interesting to see which knowledge items were judged differently in the three subgroups.

The level of preparation for teaching was judged with significant variation in the following knowledge components: pedagogical characteristics of vocational practical training, familiarity with the pedagogy of a proactive lifestyle, awareness of experiencecentered vocational practical training, awareness of the importance of personal role modeling, knowing the characteristics of the $\mathrm{X}, \mathrm{Y}$ and $\mathrm{Z}$ generations, knowing how to search for information on the internet, knowing the importance of video tutorials available on the internet, differentiation between visual and verbal learners.

In all eight items, those teachers who work in vocational classrooms only (and not in secondary vocational classrooms) displayed higher mean values, meaning that they felt their preparation for the teaching profession had been more appropriate. There were significant differences between the teachers' groups in connection with the judged importance of four knowledge items: knowing the role of self-determination when working, knowing how to foster self-controlling responsibility, knowing the openness of self-development in a profession, knowing the importance of video tutorials available on the internet. Those who work in vocational secondary classrooms only judged the importance of these four pedagogical knowledge items less favorably than the other two groups.

There were no significant between-group differences in connection to the third part of the questionnaire, i.e. the efficiency and usage of information sources were judged similarly ( $\mathrm{p}=.33$ and .14).

\section{Discussion and conclusions Highlights of the results}

The results of this study provided direct indications concerning the relative weaknesses vocational education teachers feel they possess in their professional knowledge. To summarize, these educators feel they are not sufficiently prepared for using video tutorials or dealing with problems stemming from the usage of ICT tools by younger generations. Participating teachers did not know much about leading a proactive style, even though this knowledge item is explicitly contained in the legal documents prescribing teacher knowledge.

Other parts of the questionnaire dealt with possible sources for gathering information in the interest of increasing professional development. As the questionnaire results revealed, much potential for further improvement remains in how efficient teachers consider conferences or participation in research projects to be in deepening their knowledge. Educational policy and research can help in emphasizing the importance of being involved in research projects; why vocational teachers feel they do not benefit much from attending conferences is a question for further investigation. The rare use of different information sources may in part explain the poor rating of efficiency, and vice versa. Interestingly enough, the Internet is not widely used among vocational education teachers, yet they still consider this an efficient information source.

The differences among different groups of vocational education teachers according to gender, career level and school type were significant in several cases, in spite of the fact 
that these significant differences are in great part due to the large sample size. The significant differences revealed by the influence enacted by the career level of teachers are easily interpreted in terms of growing experience and the level of motivation. In the case of gender- or school-type-related categories, the differences are relatively small for drawing any conclusions upon which decision-making could be based.

\section{Novelty}

This study formed the first large-sample investigation within the population of vocational education teachers in Hungary. The results summarized in this paper may therefore form a crucial baseline for evaluating the efficacy of future innovations and experiments. Internationally, the questionnaire used in our research can be adopted to other languages and educational system with relative ease, thus broadening the experiences and results gathered in reference to the views held by teachers working in the field of vocational education.

\section{Limitations}

Not surprisingly, the validity of the questionnaire used in this study raises similar questions to those experienced in Likert-scale close-question format questionnaires in general; this aspect therefore requires no further analysis here. It must be mentioned, however, that a second aspect-one related to the interpretation of the subscales-does deserve a note of criticism. We naturally do not claim that the labels of the five subscales fully describe the kinds of psychological constructs we were aiming to measure and accept that these labels may be open to different interpretations. At the same time, in light of the fact that reliability can be assumed, we do claim that each subscale measures something worthy of evaluation and-according to the authors' opinion-the presently applied interpretations of these subscales are meaningful.

One crucial factor must be considered to attain the generalizability of our results. The definition of VET varies from country to country (Volmari et al. 2009); selecting a population in another country to which the current results may be comparable therefore require sampling considerations be made in each country.

\section{Further research}

With this explorative study our research team developed a ready-to-use assessment tool for conducting further surveys and interventions. As a result, either the results of future interventions or the gains any educational reform may garner can be monitored, detected and evidenced via a reliable and valid means of evaluation. It is our belief that the questionnaire developed as a part of this research as well as the results obtained will serve both the renewal of Hungary's national educational system and the international discourse regarding the field's mutual endeavor to examine the views held by vocational education teachers. Further research can make use of the questionnaire as a manifest variable of either a dependent or an independent factor of educational research. The results relayed in this paper comprise a source of the base values necessary for drawing comparisons to the results found in other countries or during later, local outcomes. 


\section{Authors' contributions}

The basic research idea was developed by OK. The analysis of the theoretical background and the development of the questionnaire was done by CC, ZK and OK. Sampling and primary data analysis was done by CC. The interpretation of the results is a joint effort of CC, ZK and OK. All authors read and approved the final manuscript.

\section{Author details}

${ }^{1}$ Department of Mathematics, Faculty of Primary and Pre-School Education, ELTE, Budapest, Hungary. ${ }^{2}$ Faculty of Education and Psychology, Budapest, Hungary.

\section{Competing interests}

We wish to express the lack of any interest that might be interpreted as influencing the research.

\section{Availability of data and materials}

The data are saved in SPSS.sav format, and the questionnaires in Hungarian are available in Word.doc format. We can send them to members of the scientific discourse community upon request.

\section{Consent for publication}

All the three co-authors gave their consent for publication in written form.

\section{Ethics approval and consent to participate}

In Hungary, educational research can be conducted with volunteering consent from participants and without any further ethical approval from either a state or university committee. We followed the APA ethical standards.

\section{Funding}

This research was supported by the National Office of Vocational Education and Training and Adult Learning (Project NFA KA 5/2014). Special thanks are due to Maya J. Lo Bello for her comments on an earlier draft of this paper.

\section{Publisher's Note}

Springer Nature remains neutral with regard to jurisdictional claims in published maps and institutional affiliations.

Received: 18 June 2017 Accepted: 10 February 2018

Published online: 21 February 2018

\section{References}

8/2013 Decree of the Ministry of Economics of 6 March 2013 [8/2013 (III. 6.)] [NGM rendelet a nemzetgazdasági miniszter hatáskörébe tartozó szakképesítések mestervizsga követelményeiről]

Andersson P, Köpsén S (2015) Continuing professional development of vocational teachers: participation in a Swedish national initiative. Empir Res Vocat Educ Train 7:7

Birman BF, Desimone L, Porter AC, Garet MS (2000) Designing professional development that works. Educ Leadersh 57(8):28-33

Brickhouse NW (1990) Teachers' beliefs about the nature of science and their relationship to classroom practice. J Teach Educ 3:53-62

Cardoso L, Coutinho CP (2011) Web 2.0 learning environments in vocational education: a study on the use of collaborative online tools in the statistics module. SITE 2011:3155-3164

Cedefop (European Centre for the Development of Vocational Training) (2011) Vocational education and training in Hungary. Publications Office of the European Union

Dawes J (2008) Do data characteristics change according to the number of scale points used? An experiment using 5 point, 7 point and 10 point Scales. Int J Market Res 50:61-77

Fritsch S, Berger S, Seilfried J, Bouley F, Wuttke E, Schnick-Vollmer K, Schmitz B (2015) The impact of university teacher training on prospective teachers' CK and PCK - a comparison between Austria and Germany. Empir Res Vocat Educ Train 7:4

Golnhofer E, Nahalka I (eds) (2001) A pedagógusok pedagógiája [The pedagogy of teachers]. Nemzeti Tankönyvkiadó, Budapest

Gordon HRD (1998) Vocational education teachers' perceptions on their use assessment methods. J Vocat Tech Educ 15:8-16

Greenan JP, Wu N, Mustapha RB, Mcube LB (1998) Attitudes and motivations of vocational teachers regarding program improvement. J Ind Teach Educ 35:6-23

Guskey T (2002) Professional development and teacher change. Teach Teach Th Pract 8:381-391

Hancock ES, Gallard AJ (2004) Preservice science teachers' beliefs about teaching and learning: the influence of K-12 field experiences. J Sci Teach Educ 15:281-291

Hof S, Leiser MS (2014) Teaching in vocational education as a second career. Empir Res Vocat Educ Train 6:8

Hofer BK, Pintrich PR (2002) Personal epistemology: the psychology of beliefs about knowledge and knowing. Erlbaum, Mahwah

Imre A, Lannert J (2000) Az oktatási rendszer és a rendszerben való tanulói továbbhaladás [The educational system and students' progression in the system]. In: Halász G, Lannert J (eds) Jelentés a Magyar közoktatásról [Report on the Hungarian educational system]. Országos Közoktatási Intézet, Budapest

Littlejohn A, Beetham H, McGill M (2012) Learning at the digital frontier: a review of digital literacies in theory and practice. J Comput Assist Learn 28:547-557 
Mellado V (1998) The classroom practice of pre-service teachers and their conceptions of teaching and learning science. Sci Educ 82:197-214

Oude Groote Beverborg A, Sleegers PJC, van Veen K (2015) Promoting VET teachers' individual and social learning activities: the empowering and purposeful role of transformational leadership, interdependence, and self-efficacy. Empir Res Vocat Educ Train 7:5

Pajares MF (1992) Teachers' beliefs and educational research: cleaning up a messy construct. Rev Educ Res 62:307-332

Savasci-Acikalin F (2009) Teacher beliefs and practice in science education. Asia Pac Forum Sci Learn Teach 10:1-14

Shulman LS (1987) Knowledge and teaching: foundations of the new reform. Harv Educ Rev 57:1-21

Sirk M, Liivik R, Loogma K (2016) Changes in the professionality of vocational teachers as viewed through the experiences of long-serving vocational teachers in Estonia. Empir Res Vocat Educ Train 8:13

Volmari K, Helakorpi S, Frimodt R (eds) (2009) Competence framework for VET professions. Finnish National Board of Education, Cedefop, Thessaloniki

Wicklein RC, Rojewski JW (1995) The relationship between psychological type and professional orientation among technology education teachers. J Technol Educ 7:57-74

Submit your manuscript to a SpringerOpen ${ }^{\circ}$ journal and benefit from:

- Convenient online submission

- Rigorous peer review

- Open access: articles freely available online

- High visibility within the field

- Retaining the copyright to your article

Submit your next manuscript at $>$ springeropen.com 